* Corresponding author E-mail address:j.bartnicki@pollub.pl

Article information

Article history: AMS-Volume16-No.2-00163-12

Received 14 December 2011

Accepted 15 March 2012

\section{Forming of Semi - Finished Drill Parts by Means of Rolling - Extrusion}

\author{
Jarosław Bartnicki
}

Lublin University of Technology, 36 Nadbystrzycka, 20-618 Lublin, Poland

\section{KEY WORDS}

Rolling - extrusion, FEM, drills.

\section{ABSTRACT}

The method of semi - finished drill parts forming by means of rolling - extrusion process is show in this work. Application of Finite Element Method (FEM) allows for analyzing this process with application of different kinematics parameters. Chosen in numerical calculations cases of rolling - extrusion were verified in laboratory conditions with use of prototype aggregate PO-1. The billets for these tests were made from commercially pure lead. Obtained results confirmed possibility of rolling - extrusion technology application in proposed scope of application.

\section{Introduction}

Drills are applied in technique on a large scale. The manufacturers of these products constantly search for new solutions guaranteeing faster work and reliability at the lowest cost per piece. In order to meet these requirements it is necessary to look for new solutions, both at the designing stage and during manufacturing. Efficiency is very often the most important economical criterion, which, by no means, highlights the advantages of metal forming in comparison with machining process.

This paper presents the analysis results of the new forming process of semi-finished products of drills by means of the rolling - extrusion technology. The author concentrated on the possible to obtain helical outline and dimensional deviations, which is of great importance in economical analyses of manufactured finished products.

\section{ROLLING - EXTRUSION PROCESS}

A new proposal within the scope of drills forming is the rolling - extrusion technology $[1,2]$. In this process material is formed by means of three rotational tools. The workpiece is provided by means of a pusher pushing the billet in a working space between the profiled rolls. The rolling - extrusion process course depends on different shapes of profiled rolls and its rotary velocities correlated with pusher displacement. A schematic diagram of this process is shown in Figure 1, in which the expected movements of particular tools and the cylindrical billet are marked.

The implementation of the rolling extrusion technology is not connected, in the assumption, limiting of the product length and allows for any setting of the forming cycle, within the scope of matching of rolls rotational movement and the linear movement of pusher displacing the formed material. This solution connects in itself advantages of the cross - wedge rolling by means of three working tools [3-5] with additional possibilities guaranteed by the application of the pusher inserting the billet into the workspace. In that way, the length of the product obtained in this method is limited by a stroke of the pusher and rigidity of the rotating billet, which can undergo buckling. 


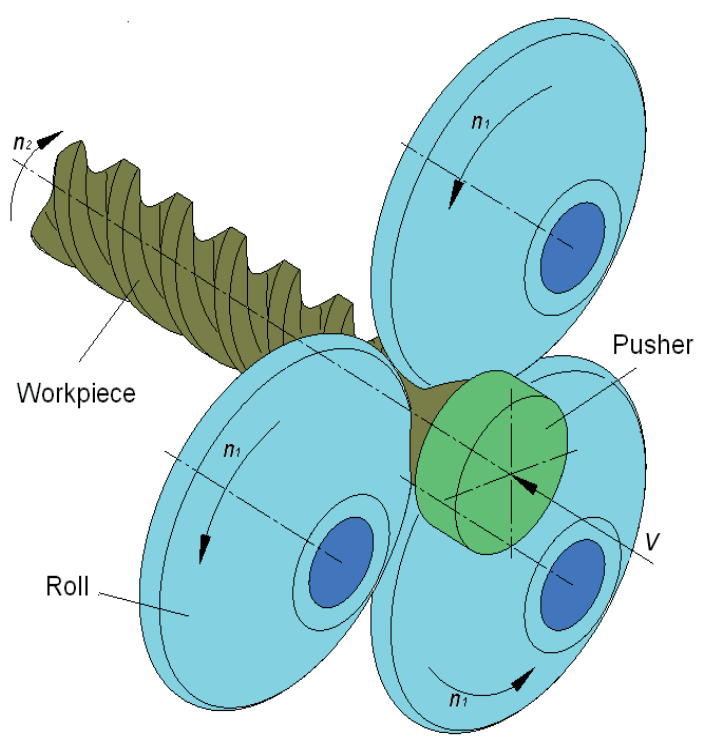

Fig. 1: Geometrical model of the rolling - extrusion process of a drill semi - finished product.

\section{Numerical analysis}

Numerical calculations of the rolling - extrusion process of drill semi-finished part, realized with the application of software DEFORM3D v. X, according to the schema given in Figure 1, were discussed. In order to achieve the result the most similar to the real one it was decided that the process would take place in conditions of heat exchange with the environment. The temperature of the forming rolls was assumed $100^{\circ} \mathrm{C}$ and the billet temperature was $1100^{\circ} \mathrm{C}$. The coefficient of heat exchange between tools and the billet was assumed equal $5000 \mathrm{~W} /$ $\mathrm{m} 2 \mathrm{~K}$ and between the billet and the environment it was $200 \mathrm{~W} / \mathrm{m} 2 \mathrm{~K}$.

Tools rolls rotary velocity $n 1$ was matched with feed velocity of the pusher $V$, obtaining in that way a parameter of feed on rotation $p$ [mm/rot.]. Depending on this parameter values, in subsequent simulation tests (Fig. 2), products were obtained which differ in terms of helical outline shape, standing for a chip space in the analyzed case.

The only element that underwent deformation was the billet - cylinder from steel C45 type, others elements such as rolls and the pusher were considered as rigid elements which did not undergo deformation. In order to observe how the product deformation would be, its external diameter was left with a sharp edge (initial chamfering was not applied). Figure 3 presents the next stages of the forming process.

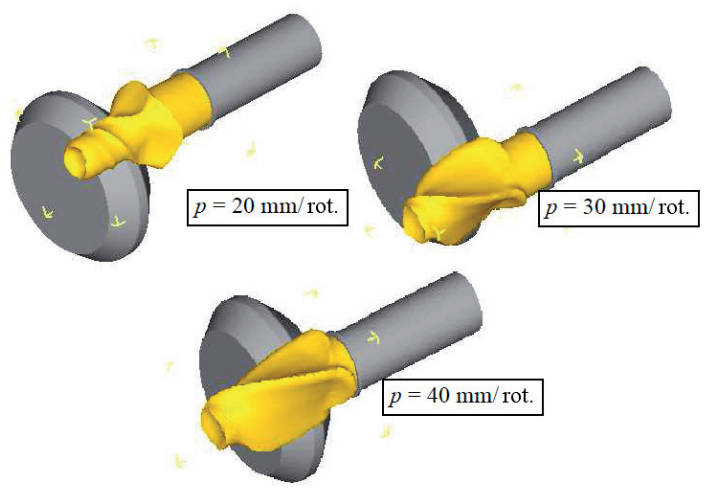

Fig. 2: Different shapes of parts formed with shown feed rate $p$. [1]

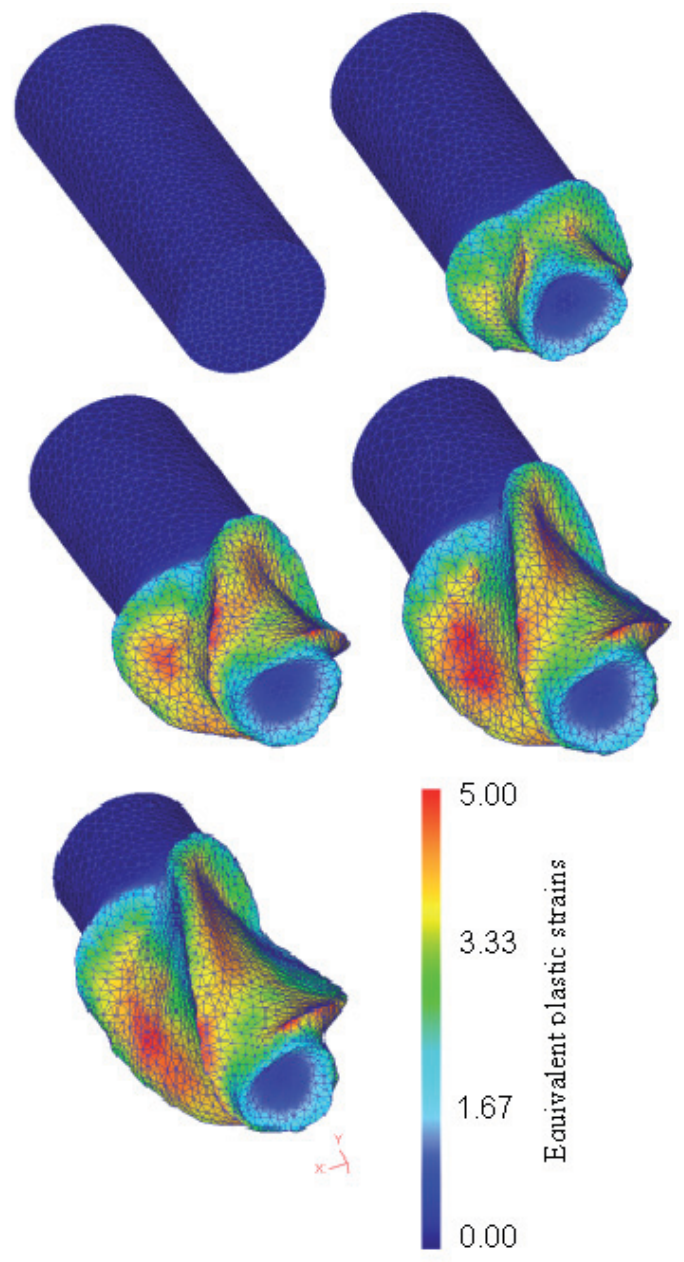

Fig. 3: Distribution of equivalent plastic strains in the following stages of the forming process of the helical outline: a-initial stage, $b-25 \%, c-50 \%, d-75 \%, e-100 \%$ of the process advancement $(p=30 \mathrm{~mm} / \mathrm{rot})$. 
The obtained results within the scope of plastic deformation of the product show that the core of the formed element remains almost not deformed. The intensive flow of the surface layers results in the appearance of the helical outline and favors the presence of a characteristic funnel at the product head.

\section{Experimental research}

Experimental research on the rolling - extrusion process of drills semi-finished parts were done with the application of an specialized aggregate PO-1 (Fig. 4 and Fig. 5), which is the laboratory equipment at the Department of Metal Forming and Computer Modelling at Lublin University of Technology.

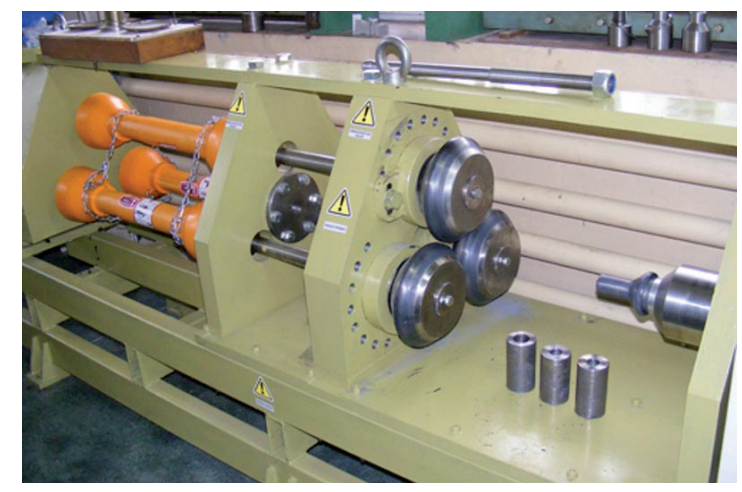

Fig. 4: General view of rolling extrusion aggregate PO-1( without hydraulic feeder).

A billet of cylindrical shape made from commercially pure lead was chosen for the initial analysis. The billets had the diameter equal

$\mathrm{d}=48 \mathrm{~mm}$ at the length $\mathrm{I}=200 \mathrm{~mm}$. Such a prepared billet was placed in the pusher seat and it underwent the forming process. Four tests were made changing the feed velocity of hydraulic actuator, which guaranteed achieving the value of feed rate on rotation $p=20 ; 25 ; 30$ and 35 , which corresponds with the subsequent marking of experimental samples shown in Fig. 6.

The application in tests of too small value of the feed rate $p=20 \mathrm{~mm} /$ rot. (sample I) led to the slip phenomenon and stopping the rotational movement of the formed part. In other experimental tests, conducted at appropriately larger values of billet feeding, satisfactory results were obtained in the form of obtained spirally formed chip spaces. At the presented stage of research works, it was stated that considerably large dimensional devia- tions reaching above $2 \mathrm{~mm}$ appeared. The further research work, with the application of steel billets, should guarantee more satisfactory results within the scope of shape faults and the mentioned earlier dimensional deviations.

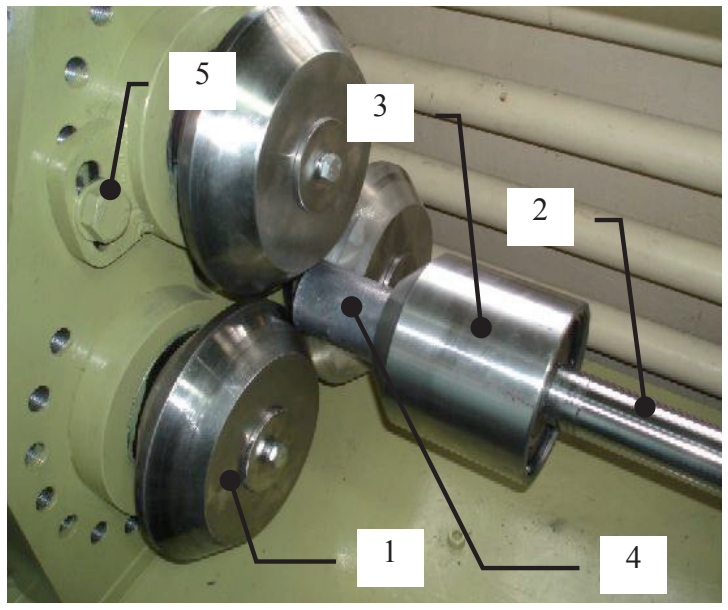

Fig. 5: Forming set with rotary tools (1), put forward hydraulic servo-motor (2) with rotary head (3), billet (4) at the position of start of forming and with eccentric mechanism (5) equipped with stroke regulation to regulate rolls spacing.

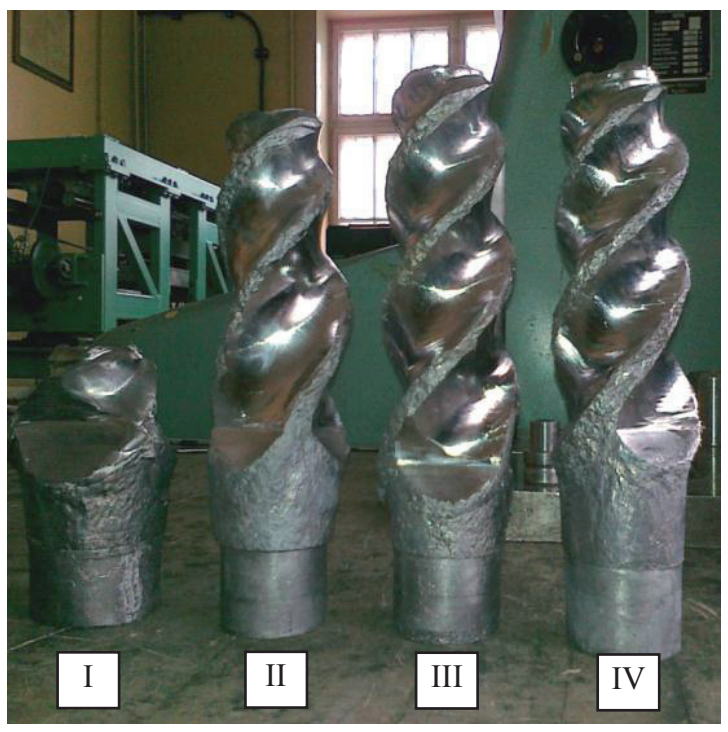

Fig. 6: Samples of drill semi finished parts after rolling-extrusion process (the description in the text).

\section{Summary}

The comparison of results of the rolling - extrusion process of products with helical line which can be used as twist drills was made. The conducted numerical calculations show the possibility 
of forming of this type of products with changeable helical outline depending on the pusher feed velocity and the forming rolls rotary velocity. On the basis of the obtained numerical results, it was planned to make experiments in the prototype aggregate $\mathrm{PO}-1$, allowing for practical realization of the rolling - extrusion process. The experimental research were done with the application of commercially pure lead. Presented, in the experimental part of this paper, tests results confirm the possibility of the initial forming of drills semi - finished parts.

The further works on determining the dependency between the process parameters and the achieved dimensional deviations of the formed products should lead to obtain products of shape close to the final outline.

\section{Acknowledge}

The investigations discussed in this paper were financed from grant no. N N508 590539

\section{References}

[1] Bartnicki J.: The theoretical and experimental research of rolling - extrusion process, Ed. Politechnika Lubelska, Lublin 2009, p. 1-118

[2] Bartnicki J., Pater Z., Gontarz A., Kazanecki J., Samołyk G.: The research on rolling - extrusion process of full and hollowed parts, Steel Research International. "Special edition: Metal Forming 2008", vol. 1, 2008, p. 364-368

[3] Pater Z. Cross - wedge rolling (in Polish), Ed. Politechnika Lubelska, Lublin 2009

[4] Danno A., Tanaka T.: Characteristics of billet deformation in 3-roll wedge rolling of axisymmetric stepped shafts, Proceedings of 3rd International Conference on Rotary Metalworking Processes 8 -10 September 1984, Kyoto Japan 1984, s. 321-332

[5] Gla R., Hahn F., Kolbe M., Meyer L. W.: Process of partial bulk metal-forming - aspects of technology and FEM simulation, Journal of Materials Processing Technology 1998 vol. $80-81$, s. $174-178$ 